\title{
LETTERS
}

\section{The buck must stop somewhere}

Dr. Kelsall's editorial ${ }^{1}$ on the recent Ontario court decision upholding the requirement for "effective referral" seems to mischaracterize the specifics of what the College of Physicians and Surgeons of Ontario (CPSO) requires of its members with regard to ensuring access to medical assistance in dying (MAiD) and other contentious medical treatments. Specifically, Dr. Kelsall mentions the requirement to "refer patients requesting MAiD directly" to a nonobjecting party. The CPSO has explicitly and repeatedly made clear that there is no requirement for an objecting physician to make a "direct referral" or a "formal referral." Instead, the CPSO states, "a physician makes an effective referral when he or she takes positive action to ensure the patient is connected in a timely manner to another physician, health care provider, or agency who is nonobjecting, accessible and available to the patient."2 This could include providing contact information for the patient to self-refer to the provincial Care Coordination Service or to a nonobjecting physician. Alternatively, a physician can designate someone else to provide this information to the patient, or ask a colleague to take over care of the patient. This is a far cry from requiring that "the physician must ask another health care provider to consider killing their patient."

However, despite the availability of these quite reasonable alternative means of ensuring access to care, some physicians who were part of the court challenge objected even to providing any information about MAiD, including the information needed for a patient to make a selfreferral. And, as Justice Wilton-Siegel rightly pointed out in his decision, there are often times when frail and vulnerable patients do not have the resources or abilities to self-refer, and do require the help of others to access MAiD. Consider, for example, the bedbound older adult in a nursing home with severe rheumatoid arthritis who cannot use a phone, let alone a computer. If his or her family, or the staff in the facility, object to facilitating the patient's access to MAiD, it may indeed fall to the patient's most responsible physician to act on the request, and rightly so.

Although I agree that physicians are not solely responsible for ensuring access to MAiD and other services that some find objectionable, they are often the last bastions of hope for those who have nowhere else to turn for assistance. Society's most vulnerable patients depend on their physicians to fulfill their fiduciary duty and respect their choices, even when those choices are difficult to accept. Physicians who, in their positions of relative authority and privilege, cannot do even the bare minimum to help their patients in this way should be prepared to face the appropriate consequences of their decisions.

\section{Edward S. Weiss MD}

Family physician and MAiD provider, Toronto, Ont.

- Cite as: CMAJ 2018 June 11;190:E726. doi: $10.1503 / \mathrm{cmaj} .69274$

\section{Reference}

1. Kelsall D. Physicians are not solely responsible for ensuring access to medical assistance in dying. CMAJ 2018;190:E181.

2. Fact sheet - ensuring access to care: effective referral. Toronto: College of Physicians and Surgeons of Ontario; 2016. Available: www.cpso. on.ca/CPSO/media/documents/Policies/Policy -Items/PAD-Effective-Referral-FactSheet.pdf (accessed 2018 Feb. 21).

Competing interests: Edward Weiss is a member of the Physicians' Advisory Council of Dying with Dignity Canada, and a member of the Canadian Association of MAID Assessors and Providers. 